\title{
POSITIVE AND NEGATIVE CHRONOTROPIC RESPONSE OF THE S-A NODE TO OXYFEDRINE
}

\author{
Kazushige SAKAI, Michitaka AKIMA, Shigeru SUGANO \\ and Yasuyuki SHIRAKI \\ Department of Pharmacology, Research Laboratories, \\ Chugai Pharmaceutical Co., Toshima-ku, Tokyo 17I, Japan
}

Accepted August 11, 1975

\begin{abstract}
Dircct perfusion of the sinus node artery under a constant pressure of 100 $\mathrm{mmHg}$ was carricd out in vagotomized dogs. "Selective" injection of L-3-methoxy(1)-(1-hydroxy-1-phenylisopropylamino) propiophenone hydrochloride (oxyfedrine) into the sinus node artery induced three types of chronotropic response; a pronounced sinus tachycardia, an initial bradycardia followed by sustained tachycardia, or a definite sinus bradycardia alone. The paradoxical sinus bradycardia induced by oxyfedrine was more pronounced at higher doses of the compound, whereas it was never produced by the injection of isoprotercnol. The oxyfedrine-induced sinus tachycardia, which occurred even in reserpinized preparations, was not suppressed by the treatment with tetrodotoxin, hexamethonium or bretylium, but it was selectively inhibited by propranolol. Atropine, tetrodotoxin or hexamcthonium did not prevent the occurrence of sinus bradycardia induced by oxyfedrine, and physostigmine failed to enhance the response. The present study indicates that the oxyfedrine-induced tachycardia is mediated mainly by a direct stimulating action on adrenergic $\beta$-receptors, while the bradycardia appears to be induced by a direct depressant action on the S-A node.
\end{abstract}

L-3-methoxy-w-(hydroxy-1-phenylisopropylamino) propiophenone hydrochloride (oxyfedrine), a drug for ischemic heart diseases (1), exhibits potent cardiac effects, i.e. positive inotropic and chronotropic as well as coronary vasodilating effects, mainly mediated by direct stimulation of adrenergic $\beta$-receptors (2-7). However, oxyfedrine may depress cardiac contraction at higher doses (2) (8).

It seemed, therefore, of interest to examine the mechanism of action of oxyfedrineinduced changes in heart rate. Experiments were performed in order to clarify whether oxyfedrine has direct or indirect effects on adrenergic or cholinergic receptors of the sinoatrial (S-A) node.

\section{MATERIALS AND METHODS}

Thirty-six mongrel dogs of both sexes, weighing 10 to $25 \mathrm{~kg}$ were anesthetized with 30 $\mathrm{mg} / \mathrm{kg}$ i.v. of sodium pentobarbital. A smaller dose was sufficient to induce anesthesia in reserpinized dogs. For 2 days before the cxperiments, reserpine was given s.c. in a daily dose of $0.25 \mathrm{mg} / \mathrm{kg}$. A tracheotomy was done and artificial respiration was given by means of a Harvard positive respirator (Model 607). The chest was opened at the right 4th intercostal space. The pericardium was cut, and a pericardial cradle was arranged so that the heart would remain in the proper position. The direct perfusion of the sinoatrial (S-A) 
node artery was arranged according to the modification of original method of James and Nadeau (9). The details of the preparation have been described elsewhere (10).

All experiments were performed under constant perfusion pressure at $100 \mathrm{mmHg}$. Initial dose of $500 \mathrm{U} / \mathrm{kg}$ of sodium heparin was administered intravenously. Harvard stylc peristaltic pump (Model 500-1200) was used for the perfusion. The flow rate in the S-A node artery was determined by using electronagnetic flowmeter (Nihon Kohden MF-25). Pressure transducers (Nihon Kohden MP-4T) were used for the measurement of perfusion pressure and systemic blood pressure at the femoral artery. ECG was reccrded by an electrocardiograph (Fukuda Electro. RS-200A) according to the bipolar apcx-base lead from the surface of the heart and the heart rate was continuously measured by a cardiotachograph (Nihon Kohden RT-2). An ink writing oscillograph (Nihon Kohden WI-1E0) was used for recording. In all experiments both vagi were cut at the midcervical level. Electrical stimulation $(30 \mathrm{~Hz}, 1 \mathrm{msec}, 2 \mathrm{~V}$ ) by the use of an electronic square-pulse generator (Nihon Kohden, MSE-2) was applied on the distal end of the cut vagus nerve through bipolar silver electrodes. All drugs for injection were made up in $0.9 \%$ saline solution and the drug solution was injected into the perfusion system to the S-A node artery in a volume of $0.01 \mathrm{ml}$ over a period of $4 \mathrm{sec}$ by the use of microsyringe (Jintan Thermo Co.). Infusion of the drug solution was given by a Harvard infusion/withdrawal pump (Model 600-900).

Drugs used were oxyfedrine hydrochloride and norephedrine hydrochloride (supplied by Chemiewerk Homburg, Frankfurt am Main), L-isoproterenol hydrochloride (Nikken Chemical), acetylcholine chloride (ACh) (Daiichi Seiyaku), dl-norepinephrine hydrochloride and tetrodotoxin (TTX) (Sankyo), hexamethonium bromide $\left(\mathrm{C}_{6}\right)$ (Yamanouchi), dimethylphenylpiperazine (DMPP) (Aldrich), bretylium tosylate (Chugai), reserpine (Ciba), atropine sulfate (Tokyo Kasei), physostigmine sulfate (Merck), propranolol hydrochloride (Sumitomo Chemicals) and tyramine hydrochloride (Daiichi Chemical).

The values given in the text and tables are expressed as mean ? standard errors. The statistical significance of the data was determined by Student's t-test.

\section{RESULTS}

Chronotropic response of the $S-A$ node to oxyfedrine and isoproterenol injected into the $S-A$ node artery

The direct injection of oxyfedrine into the S-A node artery caused a sustained increase of sinus rate, as shown in Fig. 1A. In Table 1, the maximal response to oxyfedrine is shown in comparison with that of isoproterenol in both normal and reserpinized preparations. The effect of oxyfedrine was much weaker than that of isoproterenol.

The oxyfedrine-induced sinus tachycardia was often preceded by minor but clear sinus bradycardia (Fig. 1B). Moreover, a decrease of sinus rate as the only response to oxyfedrine was also observed in a minority of cases (Fig. 1C). The frequency of incidence of negative chronotropic response appeared to increase when higher doses of oxyfedrine were injected into the artery, while isoproterenol never induced such a paradoxical response. The paradoxical response, which was almost the same for each animal during the course 


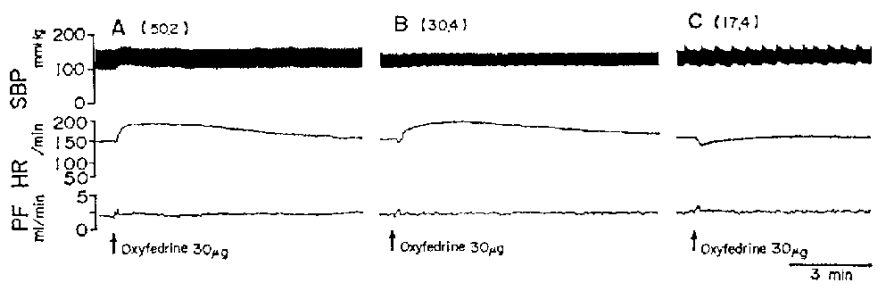

FIG. 1. Response pattern of S-A node to oxyfedrine injected into the S-A node artery. A typical result from 23 normal animals is shown in the figure. Each value in the parentheses indicates the frequency of incidence $(\%)$ of the response to oxyfedrinc: a pronounced tachycardia (A), an initial bradycardia followed by tachycardia (B) or bradycardia, only (C). SBP; systemic blood pressure, HR; heart rate, PF; sinus artery perfusion flow. (Abbreviations the same for all figures)

TABLE. 1. Sinus tachycardia induced by oxyfcdrine or isoproterenol

\begin{tabular}{|c|c|c|c|c|c|}
\hline \multirow{2}{*}{ Drugs } & \multirow{2}{*}{$\begin{array}{l}\text { Dose } \\
(\mu \mathrm{g})\end{array}$} & \multicolumn{2}{|c|}{ Normal $(\mathrm{N}=8)$} & \multicolumn{2}{|c|}{ Reserpinized $(\mathrm{N}=5)$} \\
\hline & & beats/min & per cent change & beats $\min$ & per cent change \\
\hline \multirow{5}{*}{ Oxyfedrine } & $\mathrm{C}$ & $148 \pm 9$ & & $112 \div 7$ & \\
\hline & I & $174 \pm 11$ & 17 上- 3 & $149 \pm 16$ & $31 \doteq 7$ \\
\hline & 3 & $179 \pm 12$ & $20 \div 3$ & $162 \pm 18$ & $42 \doteqdot 9$ \\
\hline & 10 & $187 \pm 11$ & $26 \div 4$ & $176 \pm 21$ & $55 \pm 10$ \\
\hline & 30 & $193+-10$ & $31 \pm 4$ & $175: 19$ & $54+9$ \\
\hline \multirow{5}{*}{ Isoproterenol } & $\mathrm{C}$ & $147 \pm 7$ & & $109+7$ & \\
\hline & 0,003 & $176+7$ & $21 \pm 4$ & $137: 12$ & $26 \pm 6$ \\
\hline & 0,01 & $198 \perp 8$ & $36+4$ & $160 \pm 6$ & $46 \pm 7$ \\
\hline & 0,03 & $217 \pm 9$ & $49.1-9$ & $192 \div 18$ & $72 \pm 2$ \\
\hline & 0,1 & $231 \div 10$ & $59 \pm 6$ & $210 \pm-11$ & $92+13$ \\
\hline
\end{tabular}

Maximum effects of oxyfedrine injected selectively into the S-A node artery were compared with those of isoproterenol in non-ircated and reserpinized animals, respectively. C: control. The results with oxyfedrine were obtained from "A type-response," as shown in Fig. 1. Each value represents mean standard crror.

TABLE 2. Frequency of incidence of sinus bradycardia induced by diffcrent doses of oxyfedrine injected into the sinus node artery

\begin{tabular}{|c|c|c|c|c|c|}
\hline & $\begin{array}{l}\text { Dose of } \\
\text { oxyfedrine }(\mu \mathrm{g})\end{array}$ & 1 & 3 & 10 & 30 \\
\hline \multirow[t]{2}{*}{ Normal } & $\begin{array}{l}\text { Frequency of } \\
\text { incidence }\end{array}$ & $1 / 9$ & $1 / 9$ & $2 / 9$ & $11 / 23$ \\
\hline & Per cent & 11.1 & 11.1 & 22.2 & 47.8 \\
\hline \multirow[t]{2}{*}{ Rcserpinized } & $\begin{array}{c}\text { Frequency of } \\
\text { incidence }\end{array}$ & $0: 5$ & $0 / 5$ & $0 / 5$ & $3 / 12$ \\
\hline & Per cent & 0 & 0 & 0 & 25.0 \\
\hline
\end{tabular}

The results were obtained from "B- and or C-type responses", as shown in Fig. 1.

The denominators in the table indicate the number of preparations used. 
of an experiment, could be observed in reserpinized as well as in normal preparations, although the incidence was less frequent (Table 2).

Studies on oxyfedrine-induced tachycardia

Effects of hexamethonium $\left(C_{5}\right)$, tetrodotoxin $(T T X)$, bretylium and propranolol: A single dose of $C_{6}(100 / 2 \mathrm{~g})$ did not inhibit the increase of sinus rate caused by oxyfedrine $(30 \mathrm{fg})$, although it completely blocked the response to DMPP $(10, \mathrm{~g})$, as shown in Fig.

2A. TTX $(1$, g) injected into the S-A node artery decreased the sinus rate, but did not affect the positive chronotropic response to oxyfedrine $(30 \%$ ) (Fig. $2 \mathrm{~B}$ ). In agreement with findings of other authors, the dose of TTX was sufficient to block the effect of electrical stimulation of the stellate ganglion of the dog (11). The injection of bretylium $(50 / \mathrm{g})$ caused a slight increase of sinus rate immediately after an intra-arterial injection into the S-A node artery, but failed to block the positive chronotropic response induced by oxyfedrine ( $30 \mu \mathrm{g})$, as shown in Fig. $2 \mathrm{C}$.

On the other hand, propranolol (10 $\mu \mathrm{g})$ injected into the artery inhibited the acceleration of sinus rhythm induced by oxyfedrine $(30, r g)$ or isoproterenol $(0.1$ /2g) (Fig. 2D). Moreover, the negative

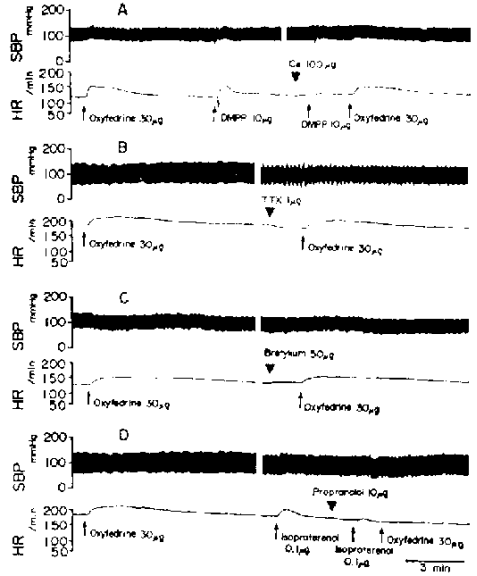

FIG. 2. Effects of hexamethonium $\left(\mathrm{C}_{6}\right)$, tetrodotoxin (TTX), brelylium and propranolol on the sinus tachycardia induced by oxyfedrine. Oxyfedrine-induced tachycardia was not blocked by $\mathrm{C}_{6}(\mathrm{~A})$, TTX (B) or bretylium (C), while propranolol completely blocked the response to oxyfedrine as well as to isoproterenol (D). The figure shows a typical result from 5 preparations. chronotropic response to oxyfedrine was enhanced by a larger dose of propranolol (60 /.g) (Fig. 3).

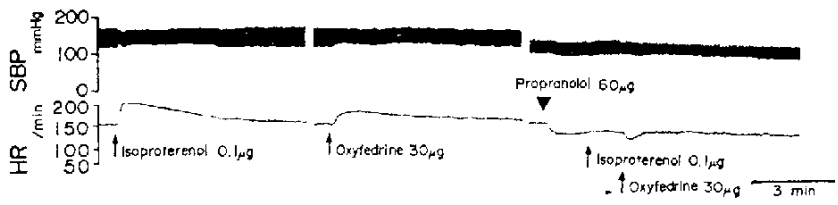

FIG. 3. Sinus bradycardia induced by oxyfedrine after propranolol. The figure shows a typical result from 3 preparations.

Response of the $S-A$ node to repeated administration of oxyfedrine: An injection of oxyfedrine $(30, \mathrm{~g})$ into the S-A node artery caused a pronounced accelcration of the sinus rhythm, which lasted for about $15 \mathrm{~min}$. When the effect of the first administration had disappeared, the same dose of oxyfedrine was injected again. As shown in Table 3, no significant changes with respect to the duration as well as to the magnitude of the response to oxyfedrine were observed $(\mathrm{P}>0.05)$. 
TABLE 3. Repeated injection of the same dose of oxyfedrine

\begin{tabular}{|c|c|c|c|c|c|}
\hline \multirow[b]{2}{*}{$\begin{array}{l}\text { Initial rate } \\
\text { (beats per min) }\end{array}$} & & \multicolumn{3}{|c|}{ Number of injection } & \multirow[b]{2}{*}{4} \\
\hline & & 1 & 2 & 3 & \\
\hline \multirow[t]{3}{*}{$176 \pm 20$} & $\begin{array}{l}\text { Max. increase } \\
\text { (beats per min) }\end{array}$ & $44+10$ & 4110 & $38 \pm 10$ & $39 \perp 9$ \\
\hline & Per cent change & $26+6$ & $23+5$ & $22 ! 5$ & $22 \pm 5$ \\
\hline & $\underset{\text { (min) }}{\text { Duration }}$ & $11.7-11.1$ & $12.6 \pm 1.3$ & $13.4 \pm 1.0$ & $13.1 \pm 1.7$ \\
\hline
\end{tabular}

Oxyfedrine ( $30 \mu \mathrm{g})$ was injected into the $\mathrm{S}-\mathrm{A}$ node artery immediately after the cffect of a preceding dose had disappeared. These results were obtained almost exclusively from "A-type responses," as shown in Fig. 1. Each value respresents mean \pm standard error from 5 animals.

Response of the $S$-A node to oxyfedrine in reserpinized animals: A positive chronotropic response to oxyfedrine $(30, n g)$ was not diminished by pretreatment with reserpine, while the response to tyramine $(10 \mu \mathrm{g})$ or norephedrine $(10 \mu \mathrm{g})$ was remarkably reduced under the same conditions (Fig. 4).

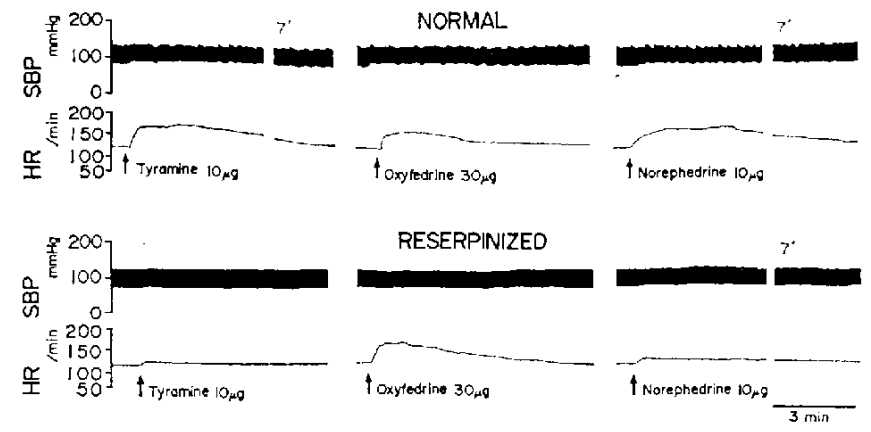

Fig. 4. Responses of the S-A node to oxyfedrine, tyramine and norephedrine in non-treated (normal) and reserpinized animals. The figure shows typical results from 2 non-treated (normal) and 2 reserpinized animals. Note that pronounced tachycardia was observed with tyramine, norephedrine or oxyfedrine in nontreated animals, whereas in reserpinized animals the responses to tyramine and norephedrine had almost disappeared.

Studies on oxyfedrine-induced bradycardia

Effects of hexamethonium $\left(C_{6}\right)$, tetrodotoxin $(T T X)$, atropine and physostigmine: $C_{6}$ $(100 \mu \mathrm{g})$ did not prevent oxyfedrine-induced bradycardia, whereas the response to DMPP $(10 \mu \mathrm{g})$ was completely inhibited (Fig. 5A). TTX $(1 / \mu \mathrm{g})$ also failed to block the negative chronotropic response caused by oxyfedrine ( $30 \mathrm{zg}$ ), as shown in Fig. $5 \mathrm{~B}$, while it completely blocked the bradycardia induced by electrical stimulation of the vagus nerve. The injection of atropine $(10 \mu \mathrm{g})$ induced a slight increase of sinus rate and completely blocked the response to acetylcholine (ACh, $1 / \mathrm{g})$. This treatment, however, never inhibited the response to oxyfedrine $(30 \mu \mathrm{g})$, as shown in Fig. $5 \mathrm{C}$. Physostigmine $(10 \mu \mathrm{g})$ decreased the 


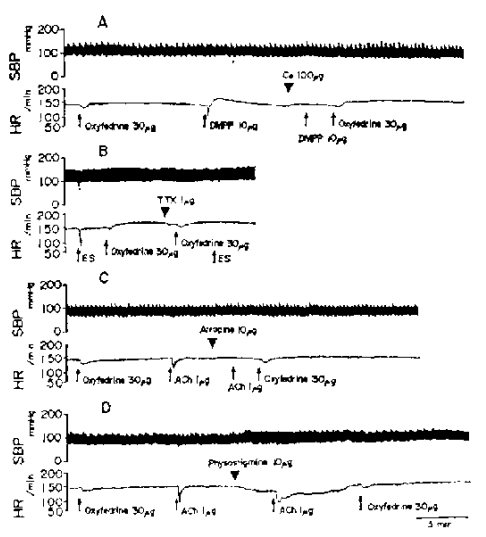

FiG. 5. Effects of hexamethonium $\left(\mathrm{C}_{6}\right)$, tetrodotoxin (TTX), atropine and physostigmine on the sinus bradycardia induced by oxyfedrine. The figure shows typical results from 5 preparations. ES; electrical stimulation of vagus nerve.

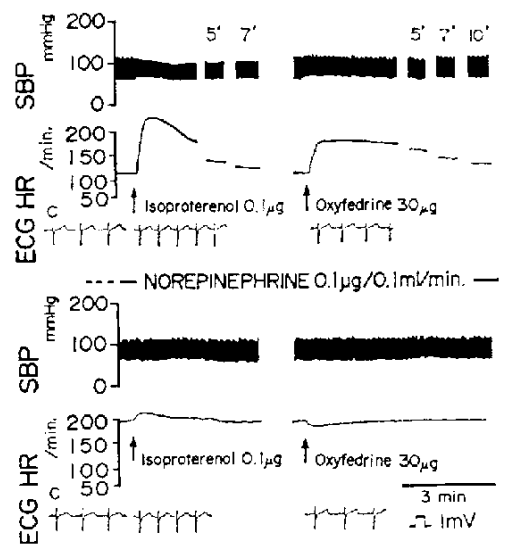

Fra. 6. Fffects of oxyfedrine and isoproterenol before and during the continuous infusion of norepinephrine into the S-A node artery. Immediately after the infusion of norepinephrine solution, a rapid increase in the sinus rate, which was maintained during the infusion, was observed. The infusion of $0.1 \mathrm{ml} / \mathrm{min}$ of $0.9 \% \mathrm{NaCl}$ solution induced no change in the sinus rate or in the sinus blood flow. The figure shows typical results from 3 preparations. Note that the effect of oxyfedrine in contrast to isoprotcenol was reversed during norepinephrine-induced sinus tachycardia. ECG; electrocardiogram.

sinus rate and cnhanced the negative chronotropic response to $\mathrm{ACh}$, while it did not modify oxyfedrine-induced bradycardia (Fig. 5D).

Effects of oxyfedrine and isoprotcrenol during continuous infusion of norepinephine: The injection of oxyfedrine $(30 / \mathrm{g})$ or isoproterenol $(0.1 / 6 \mathrm{~g})$ into the $\mathrm{S}$-A node artery induced a pronouned sinus tachycardia. After control responses of each drug were obtained, norepincphrine was continuously infused into the S-A node artery at a rate of $0.1,1 \mathrm{~g} / 0.1$ $\mathrm{ml} / \mathrm{min}$. There was a rapid increase in the sinus rate, which had stabilized during the infusion. Thus, a single injection of oxyfedrine (1 to $30 \% \mathrm{~g}$ ) induced a definite decrease of sinus rate, while isoproterenol $(0.1 / \mathrm{g})$ further increased norepinephrine-induced tachycardia (Fig. 6).

\section{DISCUSSION}

In the present experiments, a direct canine S-A node perfusion method, which was originally devised by James and Nadeau (9) and modified by Hashimoto et al. (10) for pharmacological research, was used to study the mechanism of oxyfedrine-induced changes in heart rate. This method seems adequate to study direct effects of drugs on heart rate, since these drugs can be administered selectively into the S-A node artery and therefore give almost no systemic effects. 
Injection of oxyfedrine into the S-A node artery produced three types of responses on sinus rate, as shown in Fig. 1; A) a pronounced increase of the sinus rate, B) an initial decrease followed by an increase in rate, or C) a decrease in rate, only. The pronounced positive chronotropic response induced by oxyfedrine was not influenced by the administration of either hexamethonium or tetrodotoxin. These observations exclude an indirect (reflectory) mode of action of the positive chronotropic response to oxyfedrine. Repeated administrations of oxyfedrine into the S-A node artery did not show a tachyphylaxis, neither on the magnitude nor on the duration of the acceleration of the sinus rhythm. Moreover, the positive chronotropic effect was never diminished by the pretreatment with reserpine, but was definitely inhibited by propranolol. Hence, it would appear that the oxyfedrineinduced tachycardia is indeed caused by a direct action on adrenergic $\beta$-receptors of the S-A node. These findings and conclusions are in accordance with previous results (3) (6) (7) (12).

As described in this paper, oxyfedrine also induced initial sinus bradycardia followed occasionally by a sustained tachycardia. Hashimoto et al. (13) observed similar paradoxical responses by direct injection of catecholamines (e.g. to epinephrine, dopamine but not to isoproterenol) into the canine S-A node artery and could effectively block it with a treatment of hexamethonium. In the present study, tetrodotoxin as well as hexame thonium failed to prevent the negative chronotropic response to oxyfedrine, and therefore, the oxyfedrine-induced bradycardia cannot be ascribed to a reflex mechanism.

Bradycardia was never induced by the injection of $0.01 \mathrm{ml} \mathrm{of} 0.9 \%$ saline solution over $4 \mathrm{sec}$. According to Hashimoto et al. (10) having tested the effect of saline solution on sinoatrial rhythmicity, it was concluded that the use of $0.01 \mathrm{ml}$, usually up to $0.05 \mathrm{ml} / 4 \mathrm{sec}$, failed to induce any remarkable chronotropic effect. Also, the paradoxical response to oxyfedrine cannot be ascribed to a depression of pacemaker activity due to ischemia caused by local vasoconstriction, because present sinus perfusion experiments were performed under similar conditions, at a mean perfusion fow rate of $2.58 \mathrm{ml} / \mathrm{min}( \pm 0.22$ S.E.). As shown in Fig. 1, oxyfedrine produced a slight increase but no decrease of the sinus perfusion flow even when a marked initial bradycardia occurred after the injection of oxyfedrine into the S-A node artery. Moreover, the pH of the oxyfedrine solution tested in the present experiment was 5.65 , but an intraarterial injection of the same volume of $0.9 \%$ saline solution adjusted to $\mathrm{pH} 5.65$, produced no effect on the sinus chronotropic response.

In addition to $\beta$-stimulating properties, oxyfedrine possesses some cholinesterase inhibitory property in vivo as well as in vitro (14). It seemed, therefore, of interest to use atropine or physostignine as pharmacological tools for the elucidation of the paradoxical response to oxyfedrine. The oxyfedrine-induced bradycardia was not blocked by atropine, which blocked ACh-induced bradycardia. Also, physostigmine, which prolonged the action of $\mathrm{ACh}$, failed to enhance the oxyfedrinc-induced decelcration response. Therefore, it is unlikely that the oxyfedrine-induced bradycardia is caused by a cholinergic mechanism.

According to other reports, oxyfedrine at high doses blocks adrenergic $\beta$-receptors (8) (15) (16) and such is attributed to a partial agonistic property at $\beta$-adrenoceptors (17) (18). 
In this study, sinus bradycardia could be reproducibly induced by the S-A node injection of oxyfedrine under the conditions of an accelerated sinus rhythm caused by a continuous infusion of norepinephrine, but bradycardia was never observed with the injection of isoproterenol. It may be possible, therefore, that oxyfedrine produced bradycardia partly due to the fact of its $\beta$-blocking action. However, even in the reserpinized preparations in which the myocardial catecholamine stores could be depleted over $90 \%(19)$, bradycardia was induced by high doses of oxyfedrine. This finding presunably excludes the possibility that the oxyfedrine-induced bradycardia is caused by blocking the effect of circulating catecholamines spontaneously released.

Accordingly, a direct depressant action, e.g. unspecific "membrane stabilizing" action (20) (21) (22) on the S-A node unrelated to stimulation or blockade of adrenergic or cholinergic receptors may be assumed as the sole mechanism of the oxyfedrine-induced bradycardia. This property of oxyfedrine, however, is probably masked by the predominant $\beta$-adrenergic stimulant property under most experimental conditions, especially under such bradyeardia related conditions as observed in the rescrpinized animals.

We conclude from this study that the oxyfedrine-induced tachycardia is mediated mainly by a direct stimulating action on adrenergic $\beta$-receptors, while the bradycardia appears to be induced by a direct depressant action on the S-A node.

Acknowledgements: Gratitude is due to Dr. G. Poch (University of Graz, Austria) for pertinent comments, Dr. A. v. Schlichtegroll (Chemiewerk Homburg, West Germany) for providing oxyfedrine and norephedrine, and Mrs. L. Suzuki for typing the manuscript.

\section{REFERENCES}

1) Ihiele, K., Schimassek, U. ang v. Scillichtegroll, A.: Arzheim.-Forsch. 16, 1064 (1966)

2) Thiemer, K., Stadir, R. ANo v. Schlichtegroll, A.: Arzneim.-Forsch. 18, 388 (1968)

3) Kukovetz, W.R. ANd Pöch, G.: Arzneim.-Forsch. 19, 1562 (1969)

4) Kukovetz, W.R. And Póch, G.: Action of Oxifedrine, Edited by Gerlach, E. ANd Moser, K., P. 95, F.K. Schattauer Verlag, Stuttgart-New York (1972)

5) Osswald, W. and Gumaraes, S.: Arch. Pharmacol. 270, 203 (1971)

6) Sakai, K., Sugano, S., Watavabe, 1., Fuklishima, M., Takanashi, S. and Nishit, Y.: Arch. Pharmacol. 275, $323(1972)$

7) Sakai, K., Sugano S. and Isovo, C.: Arch. Phamacol. 277, 89 (1973)

8) Sakal, K., Shiraki, Y. and Hashinoto, K.: Elurop. J. Pharmacol. 21, 81 (1973)

9) James, T.N. AND NadeaU, R.A.: Henry Ford Hosp. Med. Bull. 10, 21 (1962)

10) Hashimoto, K., Chiea, S., Tanaka, S., Hirata, M. and Suzuki, Y.: Am. J. Physiol. 215, $1183(1968)$

11) Hashmoto, K., And Chiba, S.: J. Phamacol. exp. Ther. 170, 91 (1969)

12) Kukovetz, W.R. and Pöch, G.: Arch. Pharmacol. 268, 59 (1971)

13) Hishmoto, K., Chiba, S. ANo Suzuki, Y.: Tohoku J. exp. Med. 102, 315 (1970)

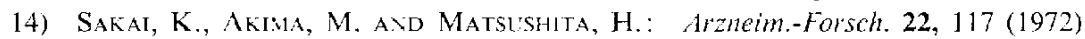

15) Bosse, J.A. And Scliaum, E.: Aich. Pharmacol. 264, 221 (1969)

16) SAKaI, K.: Japan. J. Phamucul. 20, 306 (1970)

17) Beckett, P.R. and Foster, R.W.: Europ. J. Pharmacol. 20, 161 (1972)

18) Parratt, J.R.: Brit. J. Pharmacol. 51, 5 (1974)

19) Muskls, A.J.: Arch. Phamacol. 248, 498 (1964)

20) Papp, J.G. And Szekeres, L.: Action of Oxyfedrine, Edited by Gerlach, E. And Moser, K., P. 3, F.K. Schattauer Verlag, Stuttgart-New York (1972) 
21) Poslter, P. and Vaughan Williams, E.M.: Brit. J. Pharmacol. 47, 187 (1973)

22) Homburger, H. And Antoni, H.: Action of Oxyfedrine, Edited by Gerlach, E. And Moser, K., P. 15, F.K. Schattauer Verlag, Stuttgart-New York (1972) 